\title{
Wpływ warunków i parametrów spawania punktowego metodą GTA i PTA na własności złączy zakładkowych blach ze stopu tytanu Ti-6AI-4V
}

\author{
The influence of conditions and parameters of spot \\ welding using GTA and PTA method on titanium \\ Ti-6Al-4V alloy metal sheets overlap joints properties
}

\section{Streszczenie}

W pracy badano wpływ parametrów spawania automatycznego, punktowego GTA i PTA złączy zakładkowych blach ze stopu tytanu Ti-6Al-4V na jakość, ksztalt oraz własności mechaniczne złączy. Badania przeprowadzono bez wykorzystania materiału dodatkowego.

Wykonane złącza poddano badaniom metalograficznym makro i badaniom mikrotwardości przekroju poprzecznego. Przeprowadzono i porównano ze sobą wyniki prób: wytrzymałości złączy na rozciąganie ze ścinaniem spoin, krzyżowej próby rozciągania spoin punktowych oraz technologicznej próby wyłuskiwania wykonanych spoin. W porównaniu tym uwzględniono wyniki powyższych prób przeprowadzonych dla wykonanych dodatkowo złączy zakładkowych ze zgrzeinami oporowymi punktowymi.

\section{Abstract}

This work examines the influence of the parameters of automatic welding, GTA and PTA spot welding of titanium Ti-6Al-4V alloy metal sheets overlap joints on the quality, shape and mechanical properties of joints. The analysis was conduced without utilizing the additional materials.

The joints made underwent macro metallographic examination and cross-section microhardness examination. The following tests were conducted and their results compared: combined tensile and shearing strength of welded joints, cross test of spot welds tensile strength and technological test of the welds shelling. The comparison took into account the results of the above tests conducted for additionally made overlap joints with spot resistance welds.

\section{Wstęp}

Cienkościenne konstrukcje znajdują zastosowanie w wielu gałęziach przemysłu i wykorzystywane są m.in. w budowie pojazdów samochodowych, samolotów, pojazdów kosmicznych, wagonów kolejowych, urządzeniach gospodarstwa domowego, maszynach przemysłowych, zbiornikach paliwa ciekłego, i gazowego, tunelach aerodynamicznych itp. [1]. Połączenia w konstrukcjach tego typu wykonywane są najczęściej jako połączenia nierozłączne. Spośród spawalniczych technologii wykonywania połączeń cienkościennych blach znajdują zastosowanie metody spawania łukowego, spawanie wiązką lasera, lutospawanie oraz zgrzewanie. Zależnie od potrzeb, wymagań i możliwości każda z metod łączenia może być wykorzystywana w pewnych określonych grupach zastosowań. Na wybór konkretnej metody połączenia mają wpływ takie czynniki, jak: wymagana wytrzymałość złączy, rodzaj materiału i dokładność przygotowania elementów łączonych. W konstrukcjach cienkościennych, od których wymagana jest wysoka wytrzymałość i stosunkowo mała masa oraz odporność na działanie licznych związków chemicznych, znajdują zastosowanie stopy tytanu [2,3].

Celem przeprowadzonych badań było określenie wpływu parametrów spawania punktowego GTA (spawanie elektrodą nietopliwą w osłonie gazów obojętnych) i PTA (spawanie plazmowe elektrodą nietopliwą w osłonie gazów obojętnych) bez materiału dodatkowego na własności złączy zakładkowych blach ze stopu tytanu Ti-6Al-4V 0 grubości $0,8 \mathrm{~mm}$. Wyniki przeprowadzonych badań odniesiono do innej, często stosowanej, metody łączenia punktowego cienkich blach - zgrzewania oporowego punktowego.

Prof. dr hab. inż. Andrzej Klimpel, dr inż. Damian Janicki - Katedra Spawalnictwa, Politechnika Śląska, mgr inż. Wojciech Lehrich - Instytut Spawalnictwa, Gliwice.

\section{Przebieg badań}

Próby spawania punktowego wykonywano na stanowisku zautomatyzowanym osobno dla metody spawania GTA oraz PTA bez stosowania materiału dodatkowego (rys. 1). Do wykonania złączy wykorzystano uchwyt spawalniczy do liniowego spawania metodą GTA i metodą PTA. Badania wpływu parametrów spawania na geometrię przetopień złączy przeprowadzono na próbkach ze stopu tytanu Ti-6Al-4V o wymiarach 0,8 x 50 x 100 mm. Powierzchnia blach przed procesem przetapiania została oczyszczona papierem ściernym i odttuszczona benzyną ekstrakcyjną.

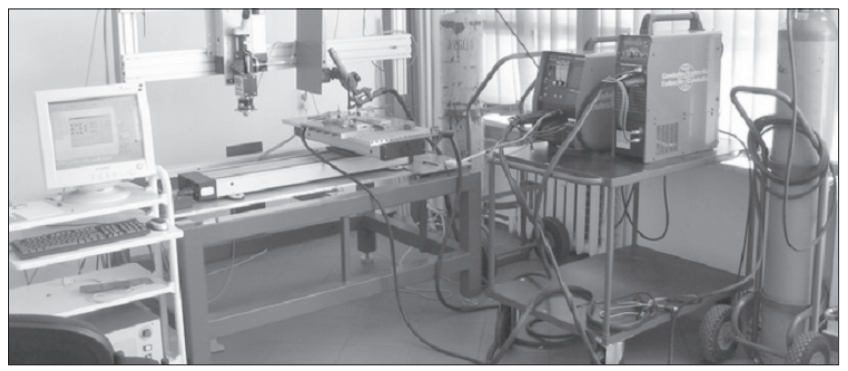

Rys. 1. Stanowisko badawcze do zautomatyzowanego spawania punktowego metodą GTA i PTA

Stopy Ti-6Al-4V charakteryzują się wysoką wytrzymałością na rozciąganie ok. $950 \mathrm{MPa}$, wysoką granicą plastyczności ok. $900 \mathrm{MPa}$ i stosunkowo niską gęstością właściwą wynoszącą ok. $4,5 \mathrm{~g} / \mathrm{cm}^{3}$. Wykorzystywane są powszechnie w przemyśle chemicznym i petrochemicznym, spożywczym, elektronicznym, i elektrotechnicznym oraz do wytwarzania sprzętu sportowego, i medycznego. Cechuje je wysoka odporność na korozję w powietrzu, wodzie morskiej, chlorkach, w większości kwasów organicznych, kwasie azotowym, rozcieńczonym kwasie siarkowym i solnym [4]. 


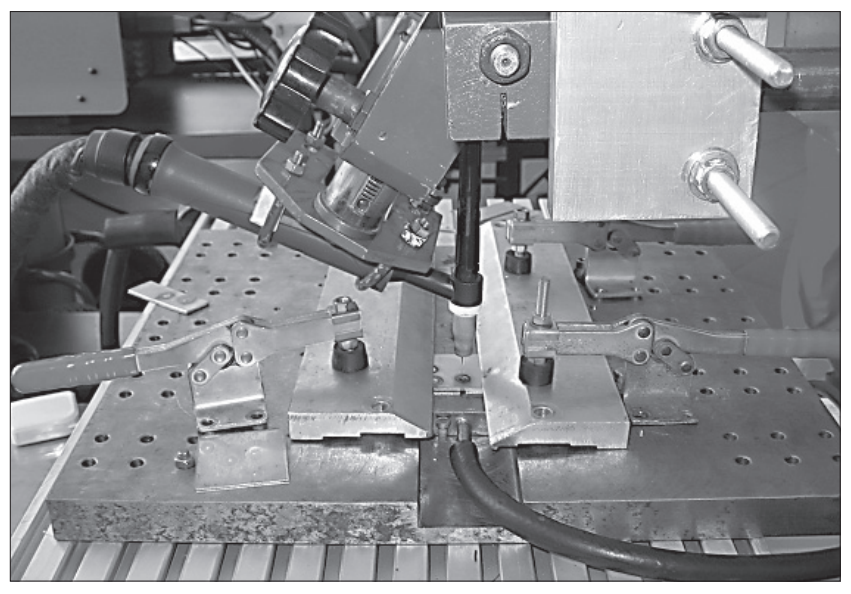

Rys. 2. Przyrząd mocujący spawane blachy z podkładką miedzianą i doprowadzeniem gazu osłonowego od strony grani

Ze względu na wysoką reaktywność stopów tytanu w temperaturze powyżej $350 \div 400^{\circ} \mathrm{C}$ podczas spawania zastosowano nadmuch gazu ochronnego od strony grani spoiny (rys. 2). Bezpośrednio po spawaniu utrzymywano przez kilka sekund nadmuch gazu ochronnego od strony lica i grani do momentu obniżenia się temperatury spawanych blach, celem uniknięcia reagowania, i rozpuszczania się wodoru, tlenu, i azotu w materiale spawanym.

Tablica I. Wpływ natężenia prądu spawania punktowego metodą GTA na średnice przekroju czynnego złącza zakładkowego blach ze stopu tytanu Ti6AI4V o grubości $0,8 \mathrm{~mm}$

\begin{tabular}{|c|c|c|c|c|}
\hline $\begin{array}{c}\text { Numer } \\
\text { spoiny }\end{array}$ & $\begin{array}{c}\text { Nateżenie prądu } \\
\text { spawania A }\end{array}$ & $\begin{array}{c}\text { Napięcie } \\
\text { tuku V }\end{array}$ & $\begin{array}{c}\text { Średnica przekroju } \\
\text { czynnego zlącza mm }\end{array}$ & $\begin{array}{c}\text { Gtębokość krateru } \\
\text { spoiny mm }\end{array}$ \\
\hline 1 & 60 & 9,8 & 2,1 & 0,17 \\
\hline 2 & 70 & 10,0 & 2,7 & 0,15 \\
\hline 3 & 80 & 10,2 & 3,1 & 0,36 \\
\hline
\end{tabular}

Uwagi: $t_{g}$ - czas główny spawania, $t_{g}=2 s ; t_{s}-$ czas trwania spadku natężenia prądu od wartości natężenia prądu głównego do natężenia $4 \mathrm{~A}, \mathrm{t}_{\mathrm{s}}=1 \mathrm{~s}$.

W pierwszym etapie badań przeprowadzono próby przetapiania pojedynczych blach w celu określenia przybliżonego zakresu parametrów procesu. Na podstawie wizualnej oceny wykonanych przetopień pojedynczych blach przyjęto zakres parametrów, przy których wykonano spawanie punktowe kolejno dla metody GTA i PTA.

W przypadku obu metod spawania próby prowadzono przy zmianie natężenia prądu spawania i stałej wartości pozostałych parametrów, a następnie przy zmiennej wartości czasu spawania, i stałej wartości pozostałych parametrów (tabl. I $\div \mathrm{V}$ ).

Wykonane złącza poddano badaniom metalograficznym, co pozwoliło określić wymiary spoin oraz wpływ parametrów natężenia prądu i czasu spawania na geometrię spoin (tabl. V). Na podstawie zdjęć makrostruktury dokonano pomiaru średnicy przekroju czynnego złączy, która stanowi główne kryterium wytrzymałości złączy na ścinanie.

Innym kryterium decydującym o wyborze wartości parametrów spawania punktowego był wynik badań wizualnych. We wszystkich spoinach punktowych wykonanych zarówno metodą GTA, jak

Tablica II. Wpływ natężenia prądu spawania punktowego metodą PTA na średnicę przekroju czynnego złącza zakładkowego blach ze stopu tytanu Ti6Al4V o grubości $0,8 \mathrm{~mm}$

\begin{tabular}{|c|c|c|c|c|}
\hline $\begin{array}{c}\text { Numer } \\
\text { spoiny }\end{array}$ & $\begin{array}{c}\text { Natężenie prądu } \\
\text { spawania A }\end{array}$ & $\begin{array}{c}\text { Napięcie } \\
\text { łuku V }\end{array}$ & $\begin{array}{c}\text { Średnica przekroju } \\
\text { czynnego złącza mm }\end{array}$ & $\begin{array}{c}\text { Głębokość krateru } \\
\text { spoiny mm }\end{array}$ \\
\hline 4 & 45 & 19,8 & 1,7 & 0,35 \\
\hline 5 & 50 & 18,0 & 2,0 & 0,41 \\
\hline 6 & 55 & 19,7 & 2,6 & 0,18 \\
\hline
\end{tabular}

Uwagi: $t_{g}$ - czas główny spawania, $t_{g}=1,5 s ; t_{s}$ - czas trwania spadku natężenia prądu od wartości natężenia prądu głównego do natężenia $4 \mathrm{~A}, \mathrm{t}_{\mathrm{s}}=1,5 \mathrm{~s}$.
Tablica III. Wpływ czasu spawania punktowego metodą GTA na średnicę przekroju czynnego złącza zakładkowego blach ze stopu tytanu Ti6Al4V o grubości $0,8 \mathrm{~mm}$

\begin{tabular}{|c|c|c|c|c|}
\hline $\begin{array}{c}\text { Numer } \\
\text { spoiny }\end{array}$ & $\begin{array}{c}\text { Czas główny } \\
\text { spawania A }\end{array}$ & $\begin{array}{c}\text { Napięcie } \\
\text { łuku V }\end{array}$ & $\begin{array}{c}\text { Średnica przekroju } \\
\text { czynnego złącza mm }\end{array}$ & $\begin{array}{c}\text { Głębokość krateru } \\
\text { spoiny mm }\end{array}$ \\
\hline 7 & 0,5 & 10,3 & 1,8 & 0,13 \\
\hline 8 & 1,0 & 10,0 & 2,6 & 0,08 \\
\hline 9 & 1,5 & 10,2 & 3,0 & 0,12 \\
\hline
\end{tabular}

Uwagi: natężenie prądu spawania $80 \mathrm{~A} ; \mathrm{t}_{\mathrm{s}}$ - czas trwania spadku natężenia prądu od wartości natężenia prądu głównego do natężenia $4 \mathrm{~A}, \mathrm{t}_{\mathrm{s}}=1 \mathrm{~s}$.

i PTA zaobserwowano krater lica. Podjęto próby jego wyeliminowania za pomocą: zastosowania opadającego przebiegu natężenia prądu w końcowej fazie cyklu spawania, wykorzystania spawania prądem stałym pulsującym, zastosowania ruchu spiralnego palnika względem powierzchni złącza.

Próby te nie pozwolity na wyeliminowanie krateru lica spoiny, którego głębokość była w zakresie 10-25\% grubości złącza. Należy zaznaczyć, że w złączach zakładkowych tego typu wykonanych metodą zgrzewania oporowego punktowego, dopuszczalna głębokość odcisku elektrod nie powinna przekraczać $20 \%$ grubości złącza.Wybrane

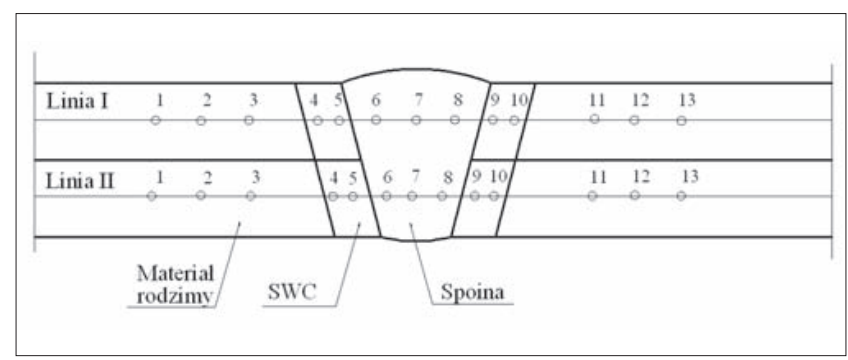

Rys. 3. Rozmieszczenie punktów pomiaru mikrotwardości złącza zakładkowego

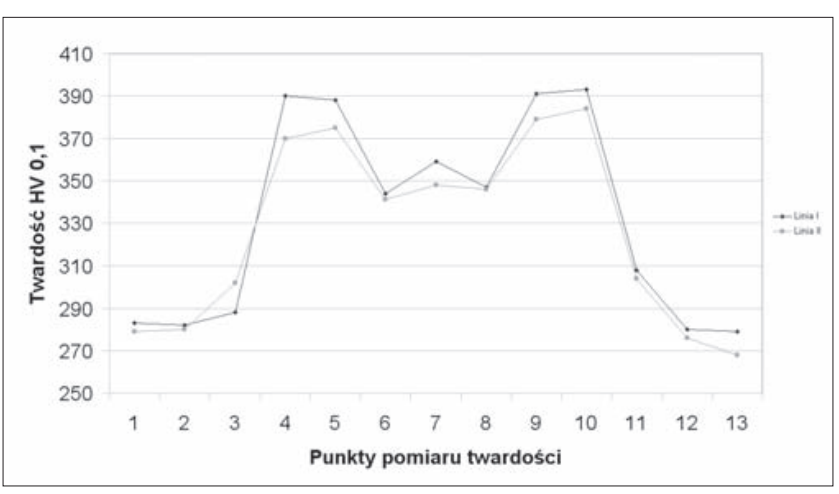

Rys. 4. Rozkład twardości złącza zakładkowego blach ze stopu tytanu Ti6Al4V 0 grubości $0,87 \mathrm{~mm}$ spawanego punktowo metodą GTA przy parametrach wg tablicy III, spoina nr 8

złącza wykonane metodą spawania punktowego GTA i PTA, poddano również badaniom mikrotwardości HV 0,1 w celu określenia rozkładu twardości w poszczególnych strefach przekroju poprzecznego próbki na liniach I i II zgodnie z rysunkiem 3. Wyniki pomiarów mikrotwardości przedstawiono na rysunkach 4 i 5.

Tablica IV. Wpływ czasu spawania punktowego metodą PTA na średnicę przekroju czynnego złącza zakładkowego blach ze stopu tytanu Ti6Al4V o grubości $0,8 \mathrm{~mm}$

\begin{tabular}{|c|c|c|c|c|}
\hline $\begin{array}{c}\text { Numer } \\
\text { spoiny }\end{array}$ & $\begin{array}{c}\text { Czas główny } \\
\text { spawania A }\end{array}$ & $\begin{array}{c}\text { Napięcie } \\
\text { łuku V }\end{array}$ & $\begin{array}{c}\text { Średnica przekroju } \\
\text { czynnego złącza mm }\end{array}$ & $\begin{array}{c}\text { Głębokość krateru } \\
\text { spoiny mm }\end{array}$ \\
\hline 10 & 1,0 & 18,8 & 1,9 & 0,15 \\
\hline 11 & 1,5 & 19,1 & 2,1 & 0,41 \\
\hline 12 & 2,0 & 19,0 & 2,5 & 0,22 \\
\hline
\end{tabular}

Uwagi: natężenie prądu spawania $50 \mathrm{~A} ; \mathrm{t}_{\mathrm{s}}$ - czas trwania spadku natężenia prądu od wartości natężenia prądu głównego do natężenia $4 \mathrm{~A}, \mathrm{t}_{\mathrm{s}}=1 \mathrm{~s}$. 
Tablica V. Makrostruktura spoin punktowych złączy zakładkowych tytanu Ti6AI4V o grubości 0,8 mm spawanego metodą GTA oraz PTA przy parametrach podanych w tablicy I $\div$ IV [pow. 12x]

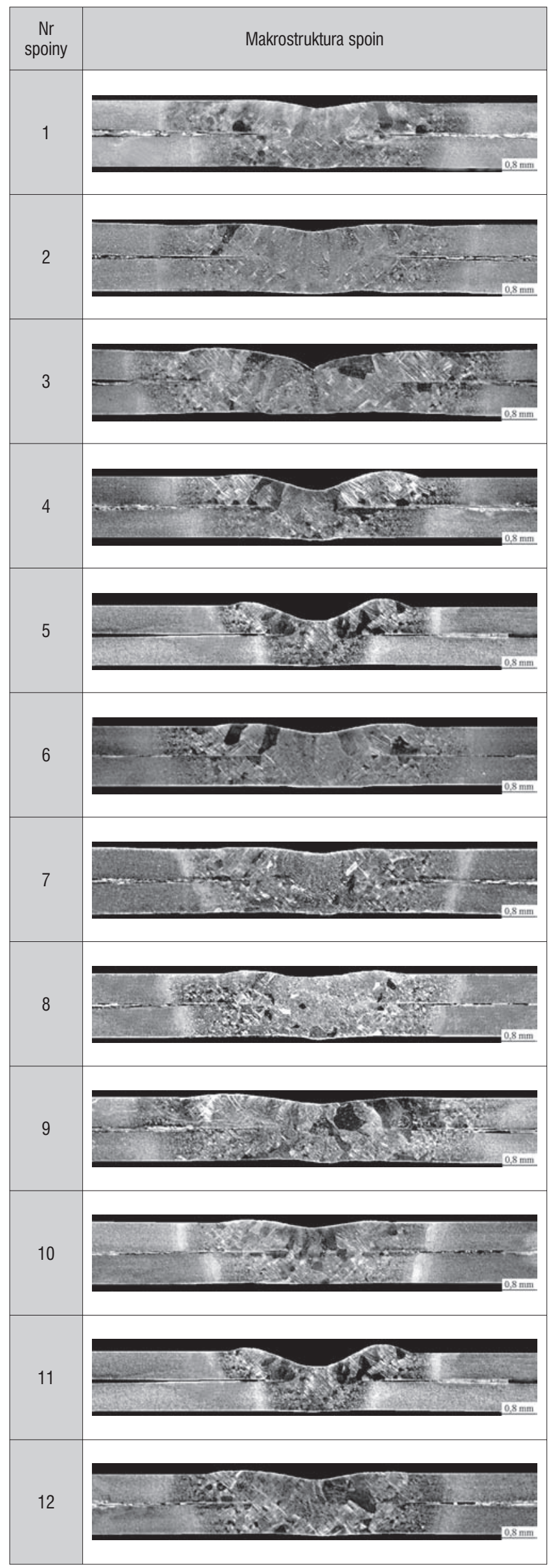

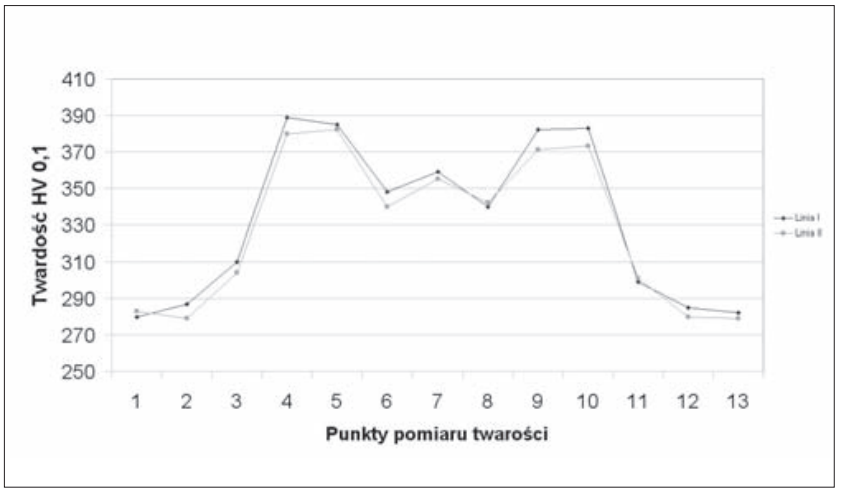

Rys. 5. Rozkład twardości złącza zakładkowego blach ze stopu tytanu Ti6AI4V o grubości 0,87 mm spawanego punktowo metodą PTA przy parametrach wg tablicy II, spoina nr 6

Tablica VI. Wyniki statycznej próby rozciągania złączy ze ścinaniem spoiny w złączach zakładkowych blach ze stopu tytanu Ti6Al4V o grubości 0,8 mm spawanych punktowo metodą GTA i PTA oraz zgrzewanych oporowo punktowo

\begin{tabular}{|l|c|c|c|c|}
\hline Oznaczenie & $\begin{array}{c}\text { Sita } \\
\text { niszcząca } \\
\mathrm{kN}\end{array}$ & $\begin{array}{c}\text { Wytrzymatość } \\
\text { spoiny na ścinanie } \\
\text { MPa }\end{array}$ & $\begin{array}{c}\text { Pole powierzchni } \\
\text { strefy zniszczenia } \\
\mathrm{mm}\end{array}$ & $\begin{array}{c}\text { Charakter } \\
\text { i sposób } \\
\text { zniszczenia }\end{array}$ \\
\hline Spoina nr 8 & 3,25 & 612,1 & 5,30 & $\begin{array}{c}\text { Czéściowe } \\
\text { rozerwanie } \\
\text { spoiny }\end{array}$ \\
\hline Spoina nr 6 & 3,65 & 687,3 & 5,31 & $\begin{array}{c}\text { Czéściowe } \\
\text { rozerwanie } \\
\text { spoiny }\end{array}$ \\
\hline Zgrzeina & 7,20 & 452,7 & 15,90 & $\begin{array}{c}\text { Rozerwanie } \\
\text { rdzenia } \\
\text { zgrzeiny }\end{array}$ \\
\hline Uwagi: Próbę przeprowadzono przy posuwie $10 \mathrm{~mm} / \mathrm{min}$ & \\
\hline
\end{tabular}

Wybrane złącza zakładkowe blach ze stopu tytanu poddano w dalszej kolejności statycznej próbie rozciągania ze ścinaniem spoiny, zgodnie z normą dotyczącą złączy zgrzewanych oporowo punktowo PN-EN ISO 14273 (tabl. VI). W celu porównania wytrzymałości na ścinanie i rozciąganie spoin punktowych wykonanych metodami GTA, i PTA ze zgrzeinami punktowymi, wykonano dodatkowo złącza zakładkowe zgrzewane oporowo punktowo, stosując natężenie prądu zgrzewania 6,0 kA, czas zgrzewania równy $98 \mathrm{~ms}$, siłę docisku zgrzewania $2,5 \mathrm{kN}$ oraz elektrodę o promieniu zaokrąglenia powierzchni roboczej równym $75 \mathrm{~mm}$.

Zgodnie z wytycznymi W-90/IS-52 Instytutu Spawalnictwa w Gliwicach pt.: „Metodyka oceny przydatności blachy do punktowego i garbowego zgrzewania na zakładkę", wykonane złącza spawane i zgrzewane punktowo poddano krzyżowej próbie rozciągania spoiny. Na podstawie tej próby stwierdzono ponad trzykrotnie niższą wytrzymałość materiału spoiny w odniesieniu do wytrzymałości na rozciąganie materiału rodzimego (tabl. VII). Przyczyną tego był widoczny na zdjęciach makrostruktury wyraźny rozrost ziarn stopu tytanu (tabl. V). Próbki poddane krzyżowej próbie rozciągania spoiny ulegały pęknięciu w obszarze SWC z jednoczesnym wyrwaniem materiału w tej strefie. Świadczy to o wyraźnym obniżeniu plastyczności materiału w wyniku silnego nagrzania obszaru spoiny [5].

Ze względu na podobieństwo obciążenia użytkowego złączy zgrzewanych i spawanych punktowo wykonane złącza poddano technologicznej próbie wyłuskiwania spoin zgodnie z normą PN-M69006, dotyczącą złączy zgrzewanych. Wyniki tej próby potwierdziły wyraźny spadek plastyczności materiału i kruchość SWC. Próbki ulegały pękaniu w SWC z brakiem wyłuskania lub tylko częściowym wyłuskaniem spoiny (zgrzeiny) (tabl. VIII). 
Tablica VII. Wyniki krzyżowej próby rozciągania spoin (zgrzein) punktowych w złączach zakładkowych blach ze stopu tytanu Ti6Al4V o grubości 0,8 mm spawanych punktowo metodą GTA i PTA oraz zgrzewanych oporowo punktowo

\begin{tabular}{|l|c|c|c|c|}
\hline Oznaczenie & $\begin{array}{c}\text { Siła } \\
\text { niszcząca } \\
\mathrm{kN}\end{array}$ & $\mathrm{R}_{\mathrm{m}} \mathrm{MPa}$ & $\begin{array}{c}\text { Średnia szerokość } \\
\text { strefy zniszczenia } \\
\mathrm{mm}\end{array}$ & $\begin{array}{c}\text { Charakter } \\
\text { i sposób } \\
\text { zniszczenia }\end{array}$ \\
\hline Spoina nr 8 & 1,35 & 254,3 & 5,30 & $\begin{array}{c}\text { Wyrwanie } \\
\text { spoiny } \\
\text { w SWC }\end{array}$ \\
\hline Spoina nr 6 & 1,45 & 273,1 & 5,30 & $\begin{array}{c}\text { Wyrwanie } \\
\text { wWC, peknię- } \\
\text { cie w SWC }\end{array}$ \\
\hline Zgrzeina & 1,75 & 110,0 & 15,90 & $\begin{array}{c}\text { Wyrwanie } \\
\text { zgrzeiny w SWC, } \\
\text { pęknięcie } \\
\text { w SWC }\end{array}$ \\
\hline $\mathrm{R}_{\mathrm{m}}$ - wytrzymałość spoiny (zgrzeiny) na rozciąganie
\end{tabular}

\section{Analiza wyników badań}

Badania metalograficzne złączy zakładkowych wykazały wpływ parametrów spawania punktowego GTA i PTA na ksztalt oraz wymiary spoiny, i SWC. Wraz ze wzrostem natężenia prądu spawania przy ustalonym czasie wykonania spoiny oraz przy wzroście czasu spawania przy stałej wartości natężenia prądu zarówno przy stosowaniu metody GTA, jak i PTA, następował wzrost przekroju czynnego złącza. Badania metalograficzne wykazały, że spoiny wykonane metodą PTA charakteryzują się relatywnie mniejszą średnicą przekroju czynnego złącza (średnica spoiny mierzona w płaszczyźnie styku łączonych blach), niż spoiny wykonane metodą GTA. Spoiny wykonane metodą spawania punktowego GTA cechowała większa średnica lica oraz mniejsza głębokość krateru niż w spoinach uzyskanych metodą PTA.

Badania mikrotwardości wybranych złączy ze spoinami punktowymi wykonanymi metodami GTA i PTA wykazaly wzrost twardości w SWC odpowiednio o ok. 40\% i 30\% w stosunku do materiału rodzimego. Twardość materiału rodzimego wynosiła $270 \div 2900,1 \mathrm{HV}$. Twardość SWC w metodach GTA i PTA zawierała się odpowiednio $380 \div 390$ 0,1 HV i 270 $\div 390$ 0,1 HV. Twardość mierzona w spoinie dla metody GTA i PTA wynosita 340 $\div 360$ 0,1 HV.

Wytrzymatość na ścinanie spoin wykonanych metodą spawania punktowego GTA i PTA była odpowiednio 0 35\% i 51\% wyższa od wytrzymałości na ścinanie zgrzein punktowych wykonanych metodą zgrzewania oporowego.

Wyniki krzyżowej próby rozciągania spoin punktowych wykazały wyższą 10\% wytrzymałość spoin wykonanych metodą PTA w stosunku do spoin wykonanych metodą GTA prądem stałym ciągłym przy tej samej średnicy czynnej złącza i tej samej głębokości przetopienia. Jednocześnie stwierdzono znaczny spadek wytrzymatości na rozciąganie wykonanych spoin w stosunku do wytrzymałości materiału rodzimego.

Technologiczna próba wyłuskiwania spoin wykazała kruchość materiału w obszarze SWC. Próbie wyłuskiwania spoin towarzyszyto najczęściej pęknięcie pojawiające się w SWC, które uniemożliwiato całkowite wyłuskanie spoiny. Wyłuskiwanie zgrzeiny punktowej wywołało podobnie pęknięcie materiału w SWC.
Tablica VIII. Wyniki technologicznej próby wyłuskiwania spoin i zgrzein w złączach zakładkowych blach ze stopu tytanu Ti6AI4V o grubości 0,8 mm spawanych punktowo metodą GTA i PTA oraz zgrzewanych oporowo punktowo

\begin{tabular}{|l|c|c|}
\hline Oznaczenie & $\begin{array}{c}\text { Charakter i spo- } \\
\text { sób zniszczenia }\end{array}$ & Widok złącza po próbie wyłuskiwania \\
\hline Spoina nr 8 & $\begin{array}{c}\text { Pęknięcie } \\
\text { w SWC }\end{array}$ & $\begin{array}{c}\text { Czésciowe } \\
\text { wyłuskanie } \\
\text { Spoiny, pęknię- } \\
\text { cie w SwC }\end{array}$ \\
\hline Zgrzeina & $\begin{array}{c}\text { Częsciowe } \\
\text { wyłuskanie } \\
\text { zgrzeiny, pek- } \\
\text { nięcie w SWC }\end{array}$ \\
\hline
\end{tabular}

\section{Wnioski}

- Spawanie metodą GTA i PTA bez materiału dodatkowego, blach ze stopu tytanu Ti-6Al-4V o grubości $0,8 \mathrm{~mm}$, pozwala na wykonanie spoin punktowych o wytrzymałości na ścinanie i rozciąganie wyższej niż wytrzymałość zgrzein punktowych wykonanych metodą zgrzewania oporowego.

- Duża ilość wprowadzonego w obszarze spoiny ciepła powoduje wyraźny spadek plastyczności materiału rodzimego i pękanie w SWC w przypadku próby ścinania, rozciągania bądź wyłuskiwania spoiny.

- Spawanie punktowe metodą GTA i PTA powoduje około $40 \%$ wzrost twardości w SWC i około 20\% wzrost twardości w spoinie w odniesieniu do materiału rodzimego.

\section{Literatura}

[1] Why aren't airplanes welded? Welding Journal, 1997, t. 76, nr 1.

[2] Surmacki Dariusz: Spawanie punktowe metodą TIG bez materiału dodatkowego. Spajanie metali i tworzyw w praktyce, 3/2004.

[3] Welded aluminium aircraft structures ready for take off. Welding Metal Farbrication, 1998, t. 66, nr 9.

[4] Dobrzański L.A. : Podstawy nauki o materiałach i metaloznawstwo. WNT 2001.

[5] Rozumek Dariusz, Hepner Maria: Wplyw mikrostruktury stopu tytanu Ti6Al-4V na rozwój pęknięć zmęczeniowych. Inżynieria Materiałowa, 2/2005.

[6] Lehrich W. : Spawanie automatyczne GTA i PTA spoin punktowych złączy zakładkowych cienkich blach ze stopu tytanu. Praca dyplomowa magisterska, promotor prof. dr hab. inż. Andrzej Klimpel. Politechnika Śląska w Gliwicach. 